Research Paper

\title{
Alterations of androgen receptor-regulated enhancer RNAs (eRNAs) contribute to enzalutamide resistance in castration- resistant prostate cancer
}

\author{
Jingwen Zhao ${ }^{1,2}$, Yu Zhao², Liguo Wang ${ }^{3}$, Jun Zhang ${ }^{4}$, R. Jeffrey Karnes ${ }^{5}$, Manish \\ Kohli ${ }^{6}$, Guixia Wang ${ }^{1}$, Haojie Huang ${ }^{2,5,7}$ \\ ${ }^{1}$ Department of Endocrinology and Metabolism, The First Hospital of Jilin University, Changchun, Jilin 130021, China \\ ${ }^{2}$ Department of Biochemistry and Molecular Biology, Mayo Clinic College of Medicine, Rochester, MN 55905, USA \\ ${ }^{3}$ Division of Biomedical Statistics and Informatics, Mayo Clinic College of Medicine, Rochester, MN 55905, USA \\ ${ }^{4}$ Department of Laboratory Medicine and Pathology, Mayo Clinic College of Medicine, Rochester, MN 55905, USA \\ ${ }^{5}$ Department of Urology, Mayo Clinic College of Medicine, Rochester, MN 55905, USA \\ ${ }^{6}$ Department of Oncology, Mayo Clinic College of Medicine, Rochester, MN 55905, USA \\ ${ }^{7}$ Mayo Clinic Cancer Center, Mayo Clinic College of Medicine, Rochester, MN 55905, USA \\ Correspondence to: Guixia Wang, e-mail: gxwang6688@yahoo.com \\ Haojie Huang, e-mail: huang.haojie@mayo.edu
}

Keywords: androgen receptor, castration resistant prostate cancer (CRPC), enzalutamide, therapy resistance, eRNA

Received: December 26, 2015

Accepted: May 02, 2016

Published: May 21, 2016

\section{ABSTRACT}

Enzalutamide is a second-generation anti-androgen for treatment of castrationresistant prostate cancer (CPRC). It prolongs survival of CRPC patients, but its overall survival benefit is relatively modest ( 4.8 months) and by 24 months most patients progress on enzalutamide. To date, however, the molecular mechanisms underlying enzalutamide resistance remain elusive. Herein, we report enzalutamide treatmentinduced alterations of androgen receptor (AR)-regulated enhancer RNAs (AR-eRNAs) and their roles in enzalutamide-resistant growth and survival of CRPC cells. AR chromatin immunoprecipitation and high throughput sequencing (ChIP-seq) and RNAseq analyses revealed that 188 and 227 AR-eRNAs were differentially expressed in enzalutamide-resistant LNCaP and C4-2 cells, respectively. The AR-eRNAs upregulated in C4-2 cells and downregulated in LNCaP cells were selected through meta-analysis. Expression of AR-eRNAs and related MRNAs in the loci of FTO, LUZP2, MARC1 and NCAM2 were further verified by real-time RT-PCR. Silencing of LUZP2 inhibited, but silencing of MARC1 increased the growth of enzalutamide-resistant C4-2 cells. Intriguingly, meta-analysis showed that expression of LUZP2 mRNA increased in primary tumors compared to normal prostate tissues, but decreased again in metastatic CRPC. Our findings suggest that eRNA alteration profiling is a viable new approach to identify functional gene loci that may not only contribute to enzalutamide-resistant growth of CRPC, but also serve as new targets for CRPC therapy.

\section{INTRODUCTION}

Prostate cancer (PC) remains the most commonly diagnosed cancer and is the second leading cause of cancer deaths in American men [1]. Androgen deprivation therapy (ADT) is the mainstay of treatment for advanced PC [2]. While blockage of the AR activities through ADT initially suppresses PC growth, disease eventually evolves into castration-resistant prostate cancer (CRPC). Recent studies suggest that extra-gonadal androgen, including PC cell intracrine mechanism, can still activate the AR pathway even at a very low concentration [3-5]. These seminal findings have led to the development of the secondgeneration hormonal therapies including enzalutamide. Enzalutamide is a competitive AR inhibitor that inhibits AR translocation to the nucleus, co-activator recruitment, AR binding to DNA and activation of AR target genes [6]. Administration of enzalutamide to CRPC patients has 
achieved a prolonged overall survival [7], yet a proportion of patients do not benefit from this treatment. The overall survival benefit is relatively modest (4.8 months) [7], and by 24 months most patients progress on enzalutamide [8]. Several studies suggest that this resistance is correlated with the upregulation of androgen-related biological activities. For instance, expression of genes involved in the androgen synthesis, such as $A K R 1 C 3, H S D 3 B$ and $C Y P 17 A 1$, was significantly elevated in enzalutamide-resistant PC cells [9]. Compared to the enzalutamide-sensitive cells, upregulation of these genes potentially results in the higher levels of testosterone or dihydrotestosterone (DHT), as well as the precursors of testosterone such as cholesterol, DHEA, and progesterone in enzalutamide-resistant PC cells. Moreover, it has been confirmed that expression of the full-length AR and its splice variants is one of the major factors that drive enzalutamide-resistance in the LNCaP model [10]. Thus, it is of pivotal importance to identify and validate alternative targets for the development of therapeutic modalities to overcome enzalutamide resistance in CRPC.

Mammalian genomes are populated with thousands of enhancers that orchestrate cell-type-specific gene expression programs [11-14]. Several findings have revealed a large repository of active enhancers that can be dynamically tuned to elicit alternative gene expression programs, which may underlie many sequential gene expression related to cell differentiation and disease progression [15]. eRNAs, a new class of non-coding RNAs that are transcribed from enhancers, were initially discovered to be actively engaged in promoting mRNA synthesis in neurons [16]. Recent advance has shown that eRNA plays an important role in tumorigenesis and anticancer drug resistance in several cancers including CRPC. For example, upon activation by a series of enhancers, FOXA1 simultaneously facilitates or restricts transcription of genes regulated by AR [17-19]. Moreover, it was recently found that FOXA1 is able to trigger dramatic reprogramming of the hormonal response by causing a massive switch in AR binding to a distinct cohort of pre-established enhancers, potentially resulting in a worse prognosis in certain advanced prostate tumors [20]. However, the role and the mechanism of eRNA in the development of enzalutamide resistance in CRPC are unknown. In the present study, we explored the alterations of AR-regulated eRNAs and mRNA expression of related genes in response to the treatment of enzalutamide and their contribution to enzalutamide-resistance in CRPC.

\section{RESULTS}

\section{Enzalutamide treatment promotes cytotoxic effect on LNCaP cells and cytostatic effect on C4-2 cells along with morphological changes}

To assess the biological effect of enzalutamide on androgen sensitive and castration-resistant PC cells,
LNCaP and C4-2 cells were employed as corresponding models to examine for their responses to short and longterm enzalutamide treatment. To determine the short-term responses to enzalutamide treatment, LNCaP and C4-2 cells were treated with enzalutamide $(10 \mu \mathrm{M})$ for 5 days and cell viability was assessed by MTS assay. The number of LNCaP cells treated with DMSO (vehicle control) increased from day 1 to 5 , and decreased when treated with $10 \mu \mathrm{M}$ enzalutamide (Figure 1A, upper panel). The number of C4-2 cells treated with DMSO also increased from day 1 to 5 , but remained static when treated with enzalutamide $(10 \mu \mathrm{M})$ (Figure 1A, lower panel). These results indicate that enzalutamide was cytotoxic to $\mathrm{LNCaP}$ cells, but cytostatic to C4-2 CRPC cells following shortterm treatment.

To determine the long-term responses to enzalutamide treatment, $\mathrm{LNCaP}$ and $\mathrm{C} 4-2$ cells were treated with $10 \mu \mathrm{M}$ enzalutamide for 28 days and neurite outgrowth was detected (Figure 1B). These results are consistent with previous studies that neuroendocrine differentiation in PC can be induced by ADT or inhibition of the AR in vitro [21-26], in PC xenografts in mice [27$31]$ and in patient samples $[32,33]$. While a very small number of LNCaP cells survived, most of them died after 28 days of enzalutamide treatment. In contrast, C4-2 cells developed into enzalutamide-resistant cells without obvious reduction of cell numbers. Thus, $\mathrm{LNCaP}$ cells are sensitive, but C4-2 CRPC cells are resistant to long-term treatment with enzalutamide.

\section{Identification of AR-regulated enhancer RNAs (AR-eRNA) affected by long-term enzalutamide treatment in LNCaP and C4-2 Cells}

To identify AR-eRNAs that are possibly responsible for development of enzalutamide resistance, LNCaP and C4-2 cells that survived after 28-day treatment of enzalutamide $(10 \mu \mathrm{M})$ were subjected to RNA-seq analyses. We also performed AR ChIP-seq in LNCaP and C4-2 cells treated with or without androgen to define the AR-regulated eRNAs. Following long-term treatment with enzalutamide, 188 and 227 AR-eRNAs were identified to be affected in LNCaP and C4-2 cells, respectively. Heat maps show differentially expressed AR-eRNAs in LNCaP (Figure 2A) and C4-2 (Figure 2B) cells after treated with enzalutamide. Furthermore, we found that 102 (54.3\%) out of 188 AR ChIP-seq peaks in LNCaP cells and 151 (66.5\%) out of 227 AR ChIP-seq peaks in C4-2 cells overlap with AR ChIP-exo peaks in LNCaP cells treated with DHT ( $\mathrm{P}<0.001)$ [34]. Given that agonist failed to induce $\mathrm{AR}$ binding in antagonist responsive regions and vice versa [34], the enhancers we report here should belong to the agonist responsive regions as defined by Chen et al [34]. This finding is not only consistent with our observation that AR binding at these sites was largely enhanced by androgen treatment in both LNCaP and C4-2 
cells (Figure 3B-3E, see below), but also consistent with the finding of Chen and colleagues that DHT-induced AR binding at these sites was inhibited by enzalutamide treatment [34]. These findings suggest that expression of the identified AR-eRNAs can be regulated by AR and may contribute to the development of enzalutamide resistance in CRPC cells.
Identification of AR-eRNAs and related mRNAs differentially regulated by enzalutamide in C4-2 and $L N C a P$ cells

Since C4-2 cells were more resistant to enzalutamide compared to LNCaP cells as shown in Figure 1, we aimed to identify upregulated oncogenic genes that may

A
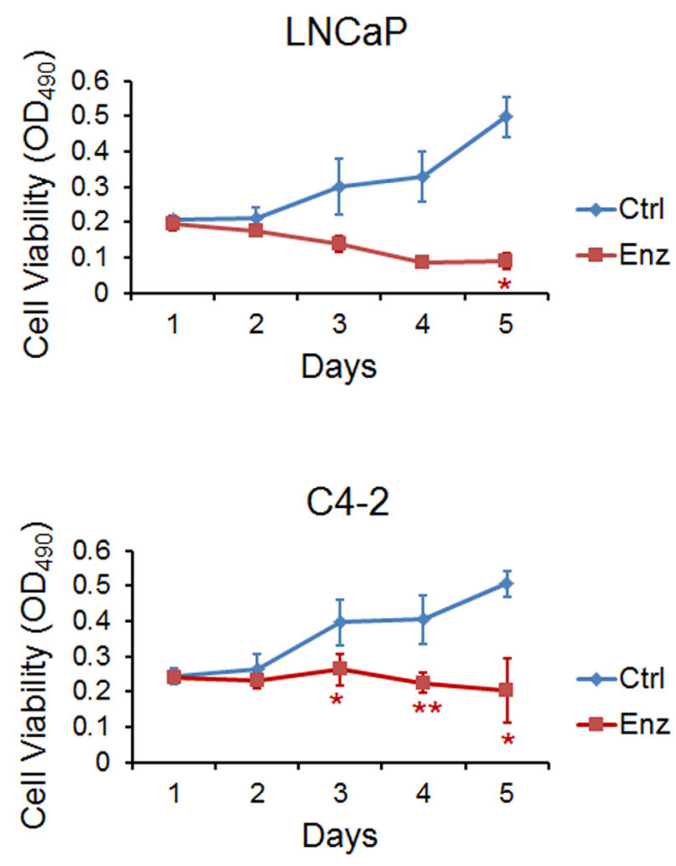

B

Mock

Enz
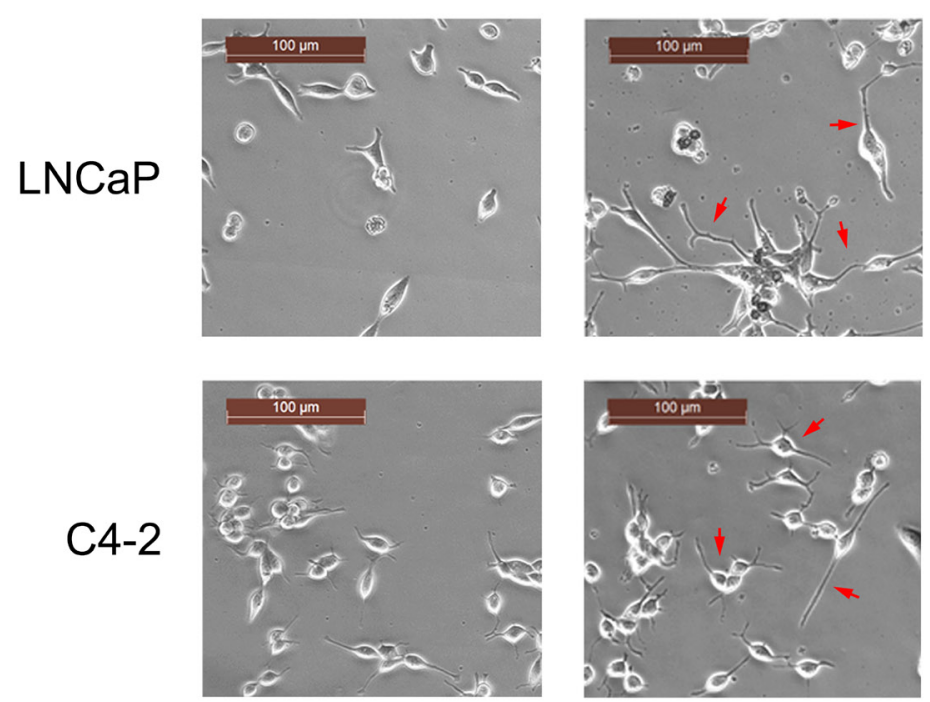

Figure 1: Enzalutamide treatment promotes cytotoxic effect on LNCaP cells and cytostatic effect on C4-2 cells along with morphological changes. A. LNCaP (Upper panel) and C4-2 cells (Lower panel) were treated with $10 \mu \mathrm{M}$ enzalutamide (Enz) for 5 days and cell viability was assessed by MTS assay. Error bars, SD from six replicates. $* P<0.05 ; * * P<0.01$. B. LNCaP and C4-2 cells were treated with $10 \mu \mathrm{M}$ enzalutamide (Enz) for 28 days and neurite outgrow (red arrows) was detected in both cell lines. Scale bars, $100 \mu \mathrm{m}$. 
contribute to enzalutamide resistance in CRPC cells. To this end, we selected AR-eRNAs upregulated in C4-2 cells while downregulated in LNCaP cells after enzalutamide long-term treatment. Heat maps show AR-eRNAs upregulated in C4-2 cells and downregulated in LNCaP cells after enzalutamide treatment and vice versa (Figure
3A). The changes are exemplified by the expression of AR-eRNAs and related mRNAs in the loci of NCAM2, FTO, MARC1 and LUZP2 (Figure 3B-3E). Enhancers at these loci are evident by enrichment of AR occupancy and enhancer histone marks H3 lysine-4 monomethylation (H3K4me1) and H3 lysine-27 acetylation (H3K27ac), but
A

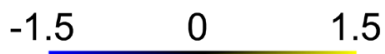

$\mathrm{B}$
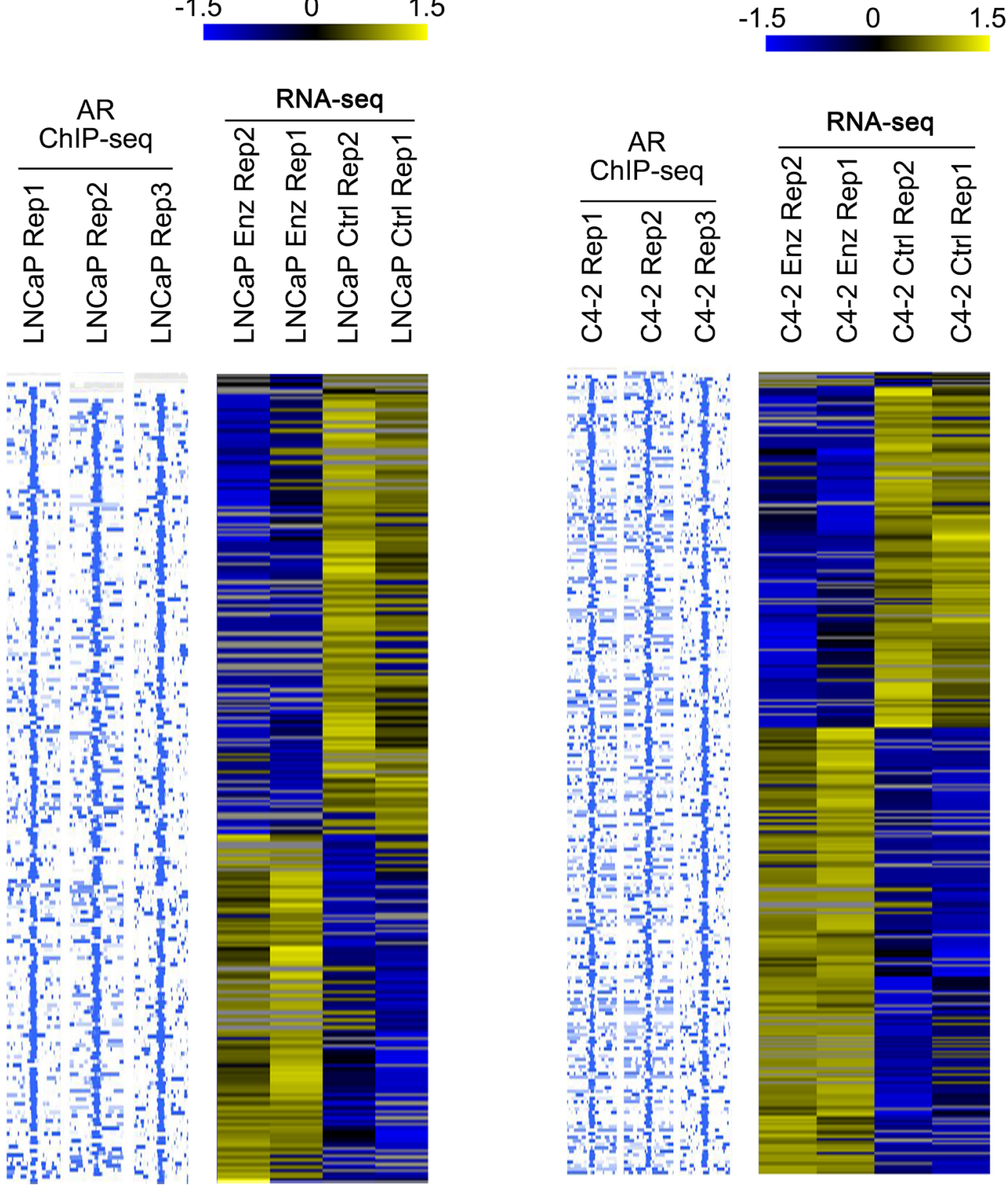
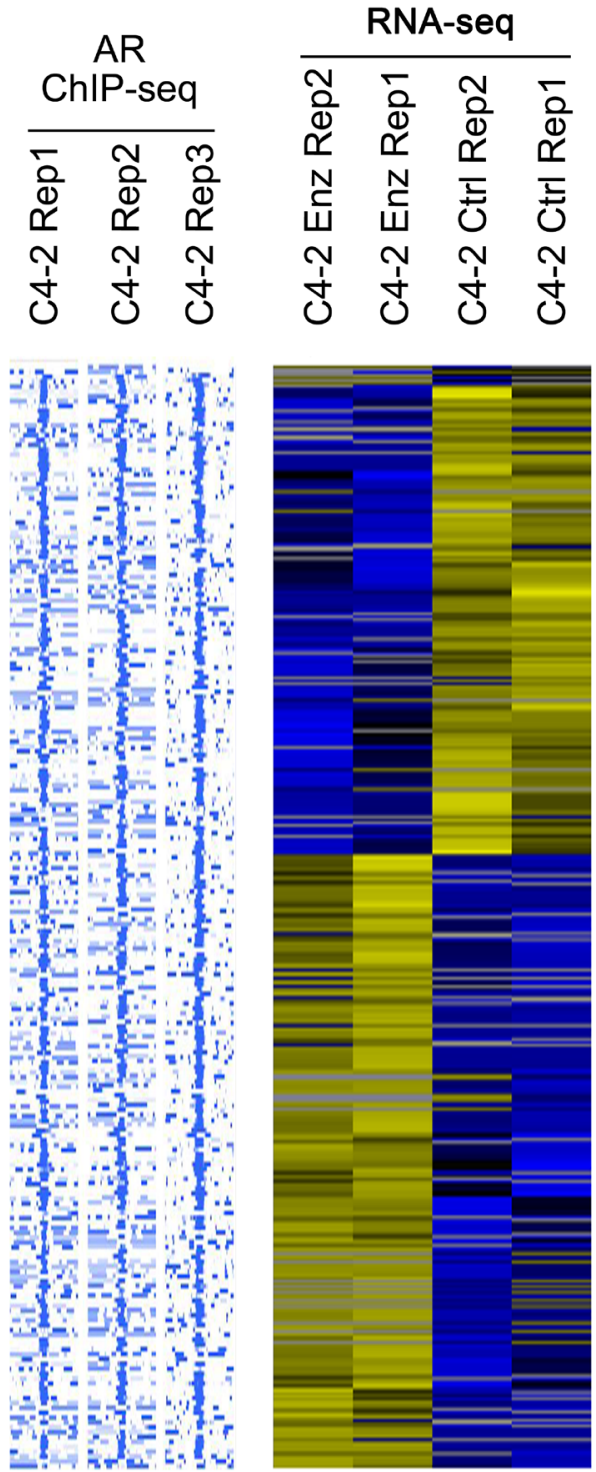

Figure 2: Identification of AR-regulated enhancer RNAs (AR-eRNAs) affected by long-term enzalutamide treatment in LNCaP and C4-2 cells. LNCaP A. and C4-2 cells B. were treated with or without enzalutamide $(10 \mu \mathrm{M})$ for 28 days and harvested for strand-specific RNA-seq experiments. To define the eRNAs expressed from AR binding sites, AR ChIP-seq was performed using anti-AR antibody (N20, Santa Cruz Biotechnology) in both LNCaP and C4-2 cells treated with androgen (1 nM mibolerone, a synthetic androgen). AR ChIP-seq and RNA-seq data analysis was performed to define up- and down-regulated AR-eRNAs in LNCaP and C4-2 cells treated with enzalutamide. Heat maps were used to show differentially expressed AR-eRNAs in LNCaP (A) and C4-2 (B) cells treated with or without enzalutamide. Each row on the heat map represents a probe set; each column represents an individual sample. Gene expression on each probe set was standardized to the mean of samples where red color is higher than the mean and green color is lower than the mean. 
little or no enrichment of the promoter mark H3 lysine-4 trimethylation (H3K4me3) (Figure 3B-3E). RNA-seq data showed that after long-term enzalutamide treatment, the AR-eRNAs in the loci of NCAM2, FTO, MARC1 and $L U Z P 2$ increased in C4-2 cells but decreased in LNCaP cells, and accordingly, the related mRNAs increased in C4-2 but decreased in LNCaP cells, with the exceptions that the AR-eRNA in the locus of LUZP2 and the related mRNA in the locus of FTO exhibited no significant change in LNCaP cells.

ChIP-qPCR assays showed that AR was readily recruited into the enhancers of these loci (primer locations in the enhancer regions at these loci are shown in Figure $3 \mathrm{~B}-3 \mathrm{E}$ ) in both LNCaP and C4-2 cells without androgen stimulation (Figure 4A). AR recruitments at these enhancers were further enhanced by treatment of cells with mibolerone, a synthetic androgen (Figure 4A). These data verify AR recruitment to the regulatory regions of the AR-eRNAs we examined.

We also performed real-time RT-PCR to confirm the differential regulation of these genes by enzalutamide in LNCaP and C4-2 cells. We treated cells with or without enzalutamide $(10 \mu \mathrm{M})$ for 28 days. We found that expression of AR-eRNAs and the corresponding mRNAs in the loci of FTO, LUZP2, MARC1 and NCAM2 were upregulated in $\mathrm{C} 4-2$ cells, but downregulated in $\mathrm{LNCaP}$ cells, except that the AR-eRNA expression in the locus of $L U Z P 2$ and the mRNA expression in the locus of

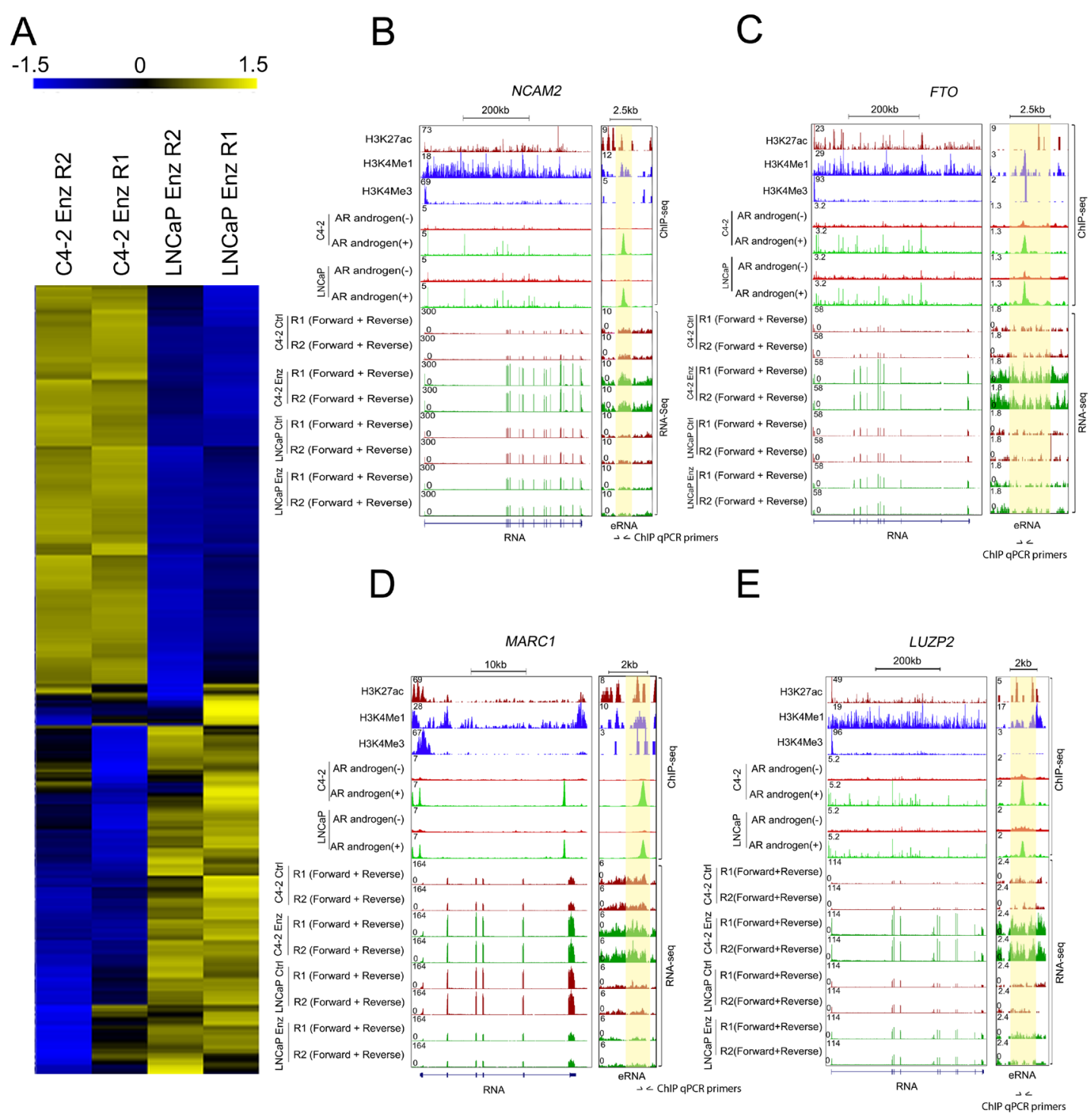

Figure 3: Identification of AR-eRNAs whose expression is altered in LNCaP and C4-2 cells after long-term treatment with enzalutamide. A. Heat maps show AR-eRNAs differentially regulated in LNCaP and C4-2 cells after long-term treatment with enzalutamide. B-E. Screenshots of the UCSC genome browser show AR-eRNAs (right panel) and related mRNAs (left panel) expression in the loci of NCAM2 (B) FTO (C) MARC1 (D) and LUZP2 (E) The area highlighted in orange indicates the enhancer region expressing AR-eRNA in each locus. 
A
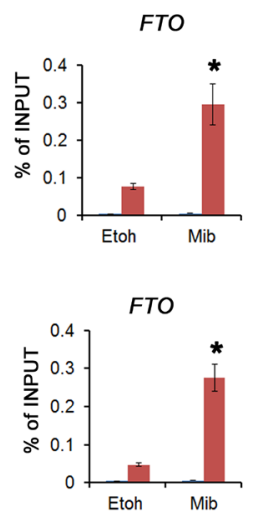

B

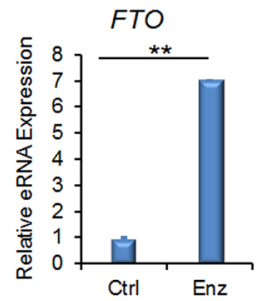

FTO

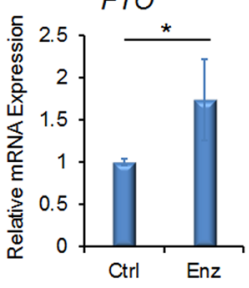

C
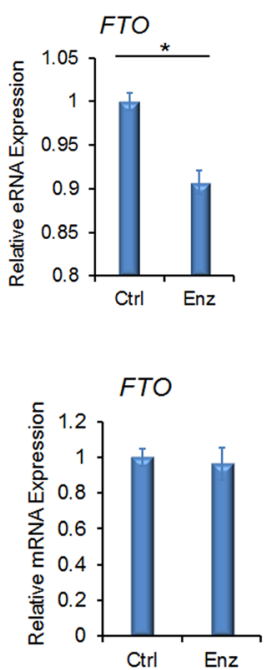

AR ChIP in LNCaP

LUZP2
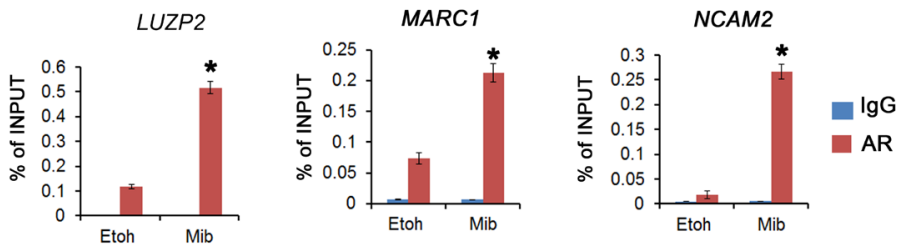

AR ChIP in C4-2
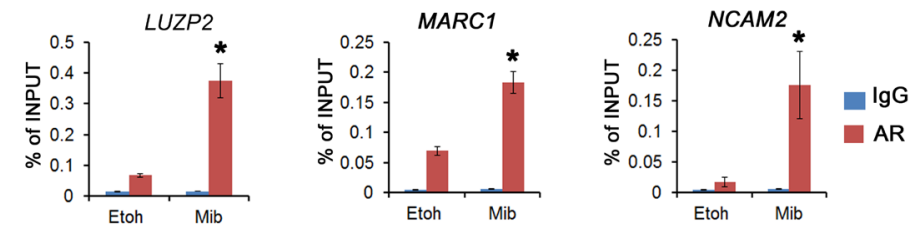

eRNA expression in C4-2
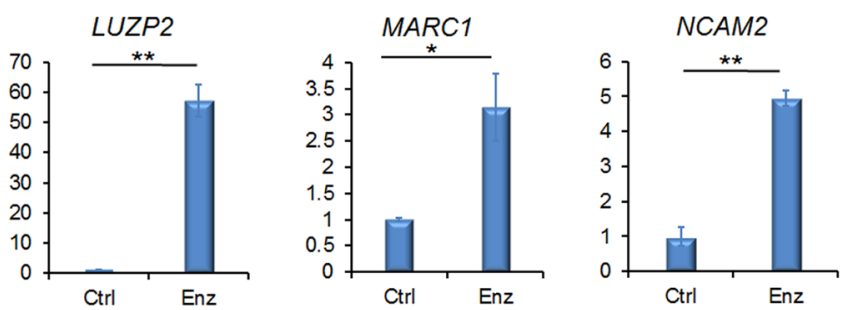

mRNA expression in C4-2
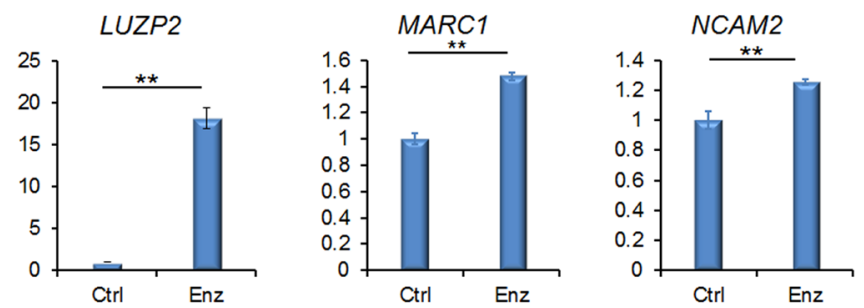

eRNA expression in $\mathrm{LNCaP}$

LUZP2

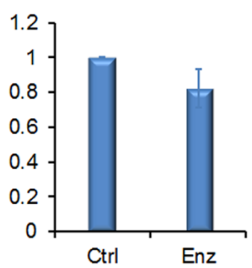

mRNA expression in $\mathrm{LNCaP}$

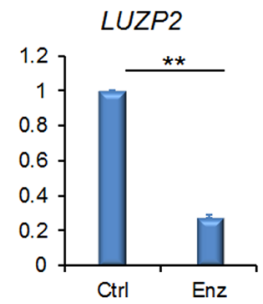

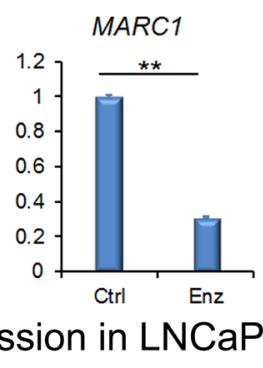
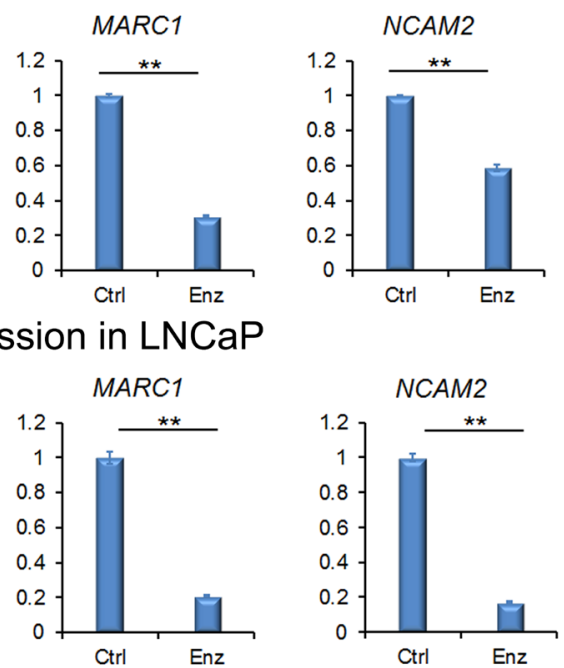

Figure 4: Verification of AR binding and expression of AR-eRNA and mRNA by quantitative PCR. A. ChIP-qPCR analysis of AR binding to enhancers in the loci of FTO, LUZP2, MARC1 and NCAM2 in both LNCaP and C4-2 cells treated with or without mibolerone $(1 \mathrm{nM})$. Immunoprecipitated DNA was detected by real-time PCR. Primer locations in the enhancer regions of these loci are shown in Figure 3B-E. All data shown are mean values $\pm \mathrm{SD}$ (error bar) from three replicates. $* P<0.01$. B. Real-time RT-PCR validation of upregulation of AR-eRNAs and mRNA of indicated genes in C4-2 cells treated with enzalutamide $(10 \mu \mathrm{M})$ for 28 days. C. Real-time RT-PCR validation of downregulation of AR-eRNAs (except $L U Z P 2$ eRNA) and mRNA (except FTO) of indicated genes in LNCaP cells treated with enzalutamide $(10 \mu \mathrm{M})$ for 28 days. Columns, mean values among three replicates; error bars, SD. * $P<0.05$; ** $P<0.01$. 
FTO remained almost unchanged in LNCaP cells (Figure $4 \mathrm{~B}, 4 \mathrm{C})$. Thus, our data confirm the regulation of four candidate gene loci FTO, LUZP2, MARC1 and NCAM2 by enzalutamide, suggesting that their expression may contribute to the development of enzalutamide resistance in CRPC cells.

\section{The enhancer-promoter interaction is enhanced in C4-2 cells after enzalutamide treatment in the loci of NCAM2 and MARC1}

Next we performed chromatin conformation capture (3C) assays to verify that the eRNA-producing regions are truly the enhancers of putative target genes examined and to assess the impact of enzalutamide treatment on the interaction between the enhancers and promoters. C4-2 and LNCaP cells were treated with or without enzalutamide $(10 \mu \mathrm{M})$ for $48 \mathrm{~h}$ and 28 days to determine the short- and long-term effect of enzalutamide on cell growth, respectively. Since both eRNA and mRNA of $M A R C 1$ and NCAM2 are consistently upregulated in C42, but downregulated in LNCaP cells after enzalutamide treatment (Figure 4), we performed 3C assay by focusing on MARC1 and NCAM2 loci. As expected, the PCR amplicons from the $3 \mathrm{C}$ assay for the crosslinking between the enhancer and promoter in the loci of NCAM2 and $M A R C 1$ were 190 and $172 \mathrm{bp}$, respectively. In the locus of NCAM2, after both short- and long-term enzalutamide treatments, the enhancer-promoter looping invariably decreased in LNCaP cells, but increased in C4-2 cells compared to the control groups (Figure $5 \mathrm{~A}, 5 \mathrm{~B}$ ). In the locus of $M A R C 1$, weak enhancer-promoter looping was detected in LNCaP cells treated with DMSO but no obvious looping in either LNCaP cells treated with enzalutamide or in C4-2 cells treated with DMSO. In contrast, enhancer-promoter looping was readily detected in C4-2 cells after both short- and long-term treatment with enzalutamide (Figure 5C, 5D). These results indicate that in the locus of NCAM2, the interaction between enhancer and promoter decreased in $\mathrm{LNCaP}$ and increased in C4-2 cells after enzalutamide treatment, and in the locus of MARC1 the interaction could only be readily observed in C4-2 cells treated with enzalutamide. These results suggest that $N C A M 2$ and $M A R C 1$ mRNAs are truly the targets of their corresponding eRNAs and their expression in response to enzalutamide may contribute to the development of enzalutamide resistance in C4-2 cells.

\section{LUZP2 knockdown suppresses and MARC1 knockdown promotes the growth of enzalutamide-resistant $\mathbf{C 4 - 2}$ cells}

To investigate the biological effect of knockdown of selected genes on the viability of enzalutamideresistant CRPC cells, C4-2 cells survived after 10-month treatment with enzalutamide $(10 \mu \mathrm{M})$ were examined for their response after treatment with shRNAs for $M A R C 1$, LUZP2, FTO, NCAM2 or non-specific (NS) shRNA in the presence of enzalutamide. Since knockdown of FTO and NCAM2 showed no significant effect on the viability of enzalutamide-resistant CRPC cells, we focused on MARC1 and $L U Z P 2$ in further studies. The knockdown effect of RNA interference in the loci of MARC1 and LUZP2 were confirmed by both RT-qPCR and western blot analysis (Figure 6A). The cell viability was assessed using MTS assays in cells treated with enzalutamide. We found that silencing of $L U Z P 2$ exerted a suppressive effect on enzalutamide-resistant growth of C4-2 CRPC cells. On the contrary, silencing of $M A R C 1$ significantly increased cell growth (Figure 6B). RT-qPCR analysis showed that there was no significant change in MARC1 eRNA and mRNA levels after C4-2 cells were treated with enzalutamide for 28 days and 10 months (Figure 6B). These results indicate that MARC1 exerts suppressive, but LUZP2 exerts promoting effect on the growth of enzalutamide-resistant CRPC cells in culture.

As LUZP2 plays a critical role in enzalutamideresistant CRPC cells, we further examined its expression in normal prostate tissues, primary PC and CRPC unexposed to enzalutamide. Our analysis of a previously reported dataset [35] indicated that expression of LUZP2 mRNA was significantly higher in primary tumors compared to normal prostate tissues, but intriguingly was lower again in metastatic CRPC compared to primary PC (Figure 6C and 6D). In line with these findings, RTqPCR analysis showed that $L U Z P 2$ mRNA expression was higher in hormone-naïve LNCaP cells than in C4-2 CRPC cells (Figure 6E), which is consistent with RNA-seq data in cells without enzalutamide treatment (Figure 3E). We also examined both $L U Z P 2$ eRNA and mRNA expression in paired 35 hormone-naïve and $35 \mathrm{~V}$ castration-resistant PDX models and demonstrated that expression of LUZP2 eRNA and mRNA were both downregulated in CRPC samples compared to the hormone-naive counterparts (Figure 6F). Furthermore, we compared the expression of RNAs extracted from primary PC and CRPC patient tissues. We demonstrated that LUZP2 mRNA expression was significantly higher in hormone-naïve $\mathrm{PC}$ patients compared with their CRPC counterparts (Figure 6G). Therefore, our data consistently showed that expression of LUZP2 mRNA was much higher in hormone-naïve PC cells in culture, PDX models in mice and patient tissues in comparison to the CRPC counterparts, suggesting that downregulation of $L U Z P 2$ might be a contributing factor in the development process from PC to CRPC, but its upregulation may be important for development of enzalutamide resistance.

\section{DISCUSSION}

ADT remains the standard care for advanced PC, resulting in remission of the disease in approximately 
$90 \%$ of patients [36]. Unfortunately, 2-3 years after treatment, CRPC develops in most patients [37, 38]. CRPC is associated with poor prognosis [39], with the median survival time varying from 9 to 30 months and metastases in over $84 \%$ of CRPC patients which reduces the mean survival to around 14 months [40]. As a new-generation hormonal therapy, enzalutamide offers an alternative in the treatment for patients with CRPC. Unfortunately, most of them still develop resistance, stressing that further development of medical interventions of CRPC is necessary. In the realm of $\mathrm{PC}$ epigenomics, extensive researches have been carried out in DNA methylation, histone modifications and microRNAs [41]. The enhancer related epigenomic studies, however, remain a gap in the field of PC research. One of the most exciting discoveries in the past few years is that enhancers produce non-coding RNAs, referred to as enhancer RNAs or eRNAs [16, 20, 42]. It is generally accepted that enhancers are largely responsible for celltype-specific gene expression $[11,14,43]$. It has been reported that DNA topoisomerase I is recruited to AR-bound functional enhancers and its activity plays an important role in regulating eRNA expression in response to DHT treatment in LNCaP cell model [44]. Hsieh et al. found that the activity of $P S A$ eRNA selectively affected AR-regulated gene including $N K X 3.1, F K B P 5$ and PLZF (also known as $Z B T B 16$ ) [45]. However, the role of the affected eRNAs in development of resistance to the second line hormonal therapy such as enzalutamide remains to be determined. In our study, we first employed a systems biology approach to profile the differential expression of functional eRNAs at $\mathrm{AR}$ binding enhancers in enzalutamide-sensitive $\mathrm{LNCaP}$ and enzalutamide-resistant C4-2 CRPC cells. We also examined their association with nearby genes by performing high throughput screening, 3C assay and functional validation. Different from the studies mentioned above, the goal of our current study is to exploit eRNA alterations as a novel approach to identify new gene targets that are involved in the development of resistance in CRPC.
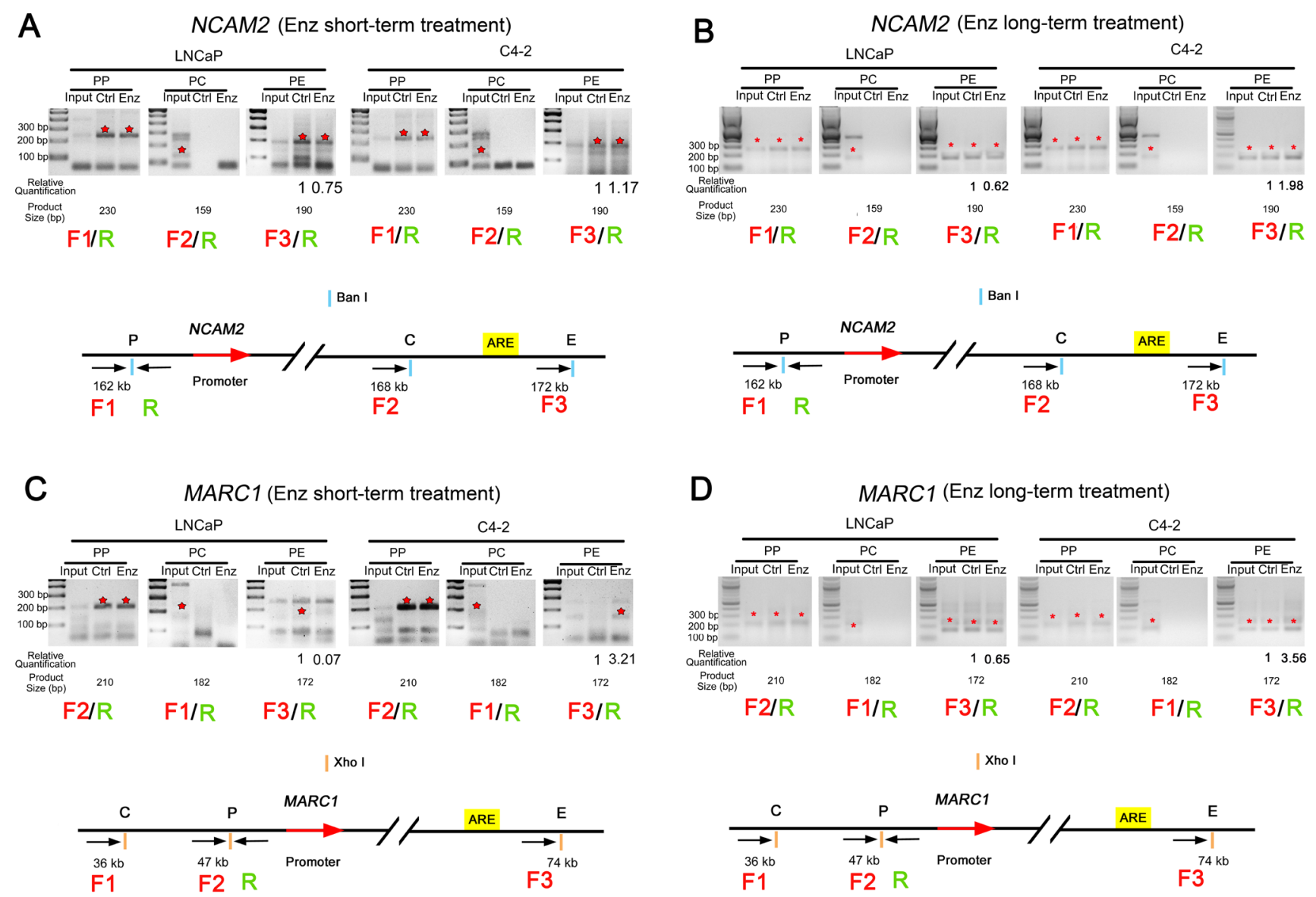

Figure 5: Enzalutamide treatment enhances enhancer-promoter interaction in the loci of $N C A M 2$ and $M A R C 1$ in C4-2 cells. The enhancer-promoter looping in the indicated gene loci was measured by $3 \mathrm{C}$ assay. The expected PCR amplicons of DNA obtained from 3C assay at the loci of NCAM2 and MARC1 are 190 and $172 \mathrm{bp}$, respectively. A and B. 3C assays in the NCAM2 locus in both LNCaP and C4-2 cells treated with DMSO or enzalutamide (10 $\mu \mathrm{M})$ for $48 \mathrm{~h}(\mathrm{~A})$ or 28 days (B). C and D. $3 \mathrm{C}$ assays in the MARC1 locus in LNCaP and C4-2 cells treated with DMSO or enzalutamide (10 $\mu \mathrm{M})$ for $48 \mathrm{~h}(\mathrm{C})$ or 28 days (D). PP: crosslinking at promoter alone; PC: crosslinking between promoter and control (middle) sites; PE: crosslinking between promoter and enhancer. LNCaP Ctrl: LNCaP cells treated with DMSO; LNCaP Enz: LNCaP cells treated with enzalutamide; C4-2 Ctrl: C4-2 cells treated with DMSO; C4-2 Enz: C4-2 cells treated with enzalutamide. Asterisks in red: PCR products are at the expected size. 
A

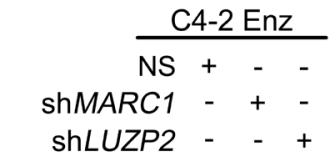

MARC1

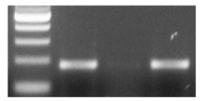

LUZP2

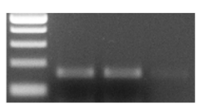

GAPDH

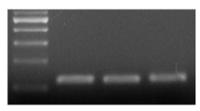

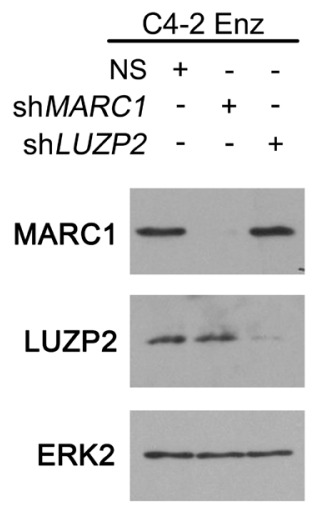

B
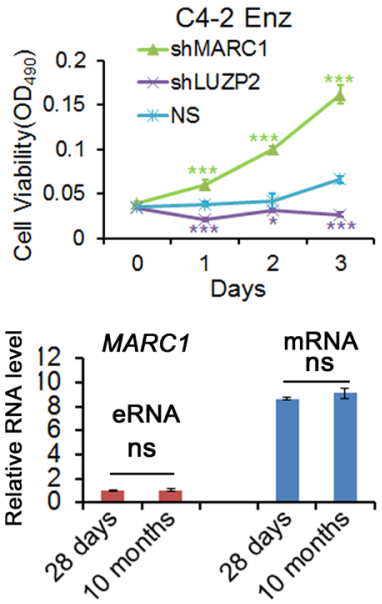

C

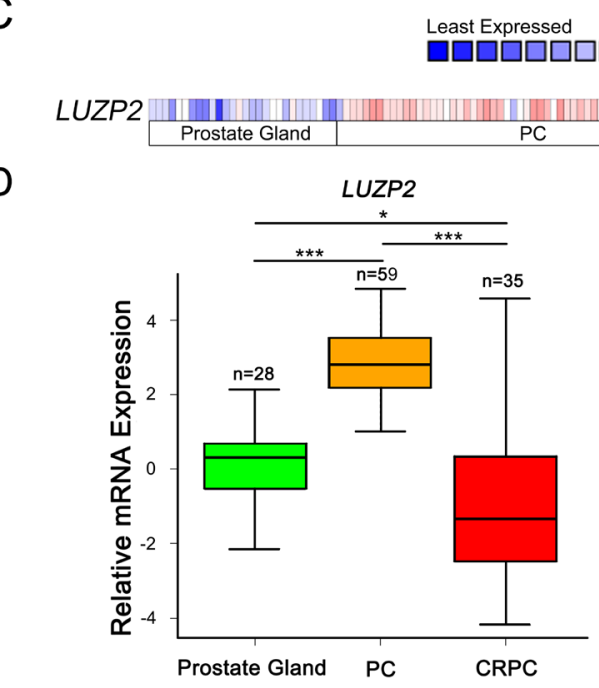

F LUZP2 ERNA

LUZP2 mRNA
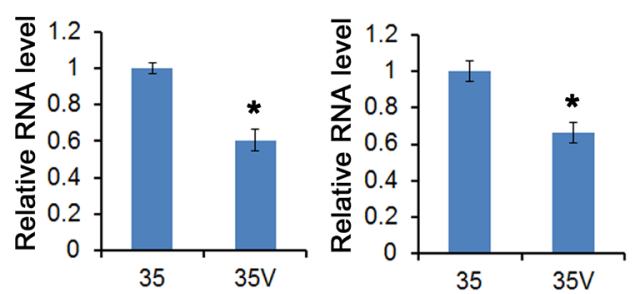

G

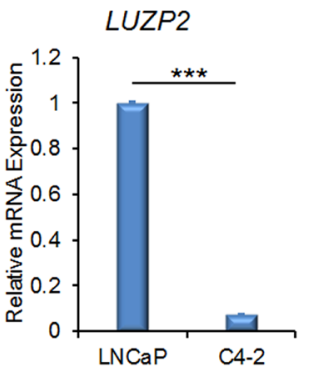

LUZP2

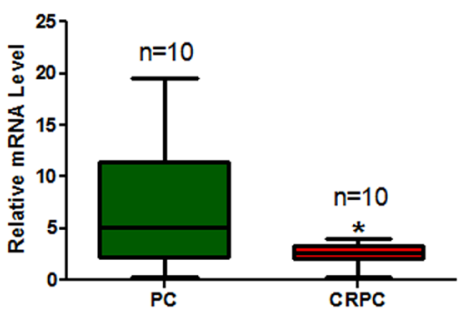

Figure 6: $L U Z P 2$ knockdown suppresses and $M A R C 1$ knockdown enhances growth of enzalutamide-resistant C4-2 cells. A. Assessment of the effect of shRNA-mediated knockdown of MARC1 and LUZP2 by RT-qPCR and western blot analysis. Enzalutamide long-term treated C4-2 cells were treated with shRNAs for MARC1, LUZP2 or non-specific (NS) control shRNAs. Expression of MARC1, LUZP2 and GAPDH (control for off-target effect) was examined by RT-qPCR (left) and western blot (right) analysis. ERK2 was used as a protein loading control. B. Top panel, enzalutamide $(10 \mu \mathrm{M})$ long-term $(10$ months $)$ treated C4-2 cells were infected with non-specific (NS) control or MARC1 or LUZP2-specific shRNAs for 2 days and cell viability was measured using MTS assay for 3 additional days. Error bars, SD from six replicates. ${ }^{*} P<0.05$; ${ }^{* *} P<0.01$. Bottom panel, RT-qPCR analysis of expression of $M A R C 1$ eRNA and mRNA in C4-2 cells treated with enzalutamide for 28 days and 10 months. ns: no significant difference. C. Heat map showing expression of $L U Z P 2$ mRNAs in a cohort of human normal prostate tissues, hormone-naïve primary prostate cancer (PC) and metastatic CRPC tissues reported by Grasso et al [35]. D. Box plots of $L U Z P 2$ mRNA expression in human normal prostate tissues, primary hormone-naïve PC and CRPC tissues reported by Grasso et al [35]. Outliers were omitted from box plots. ${ }^{*} P<0.05$; *** $P<0.001$. E. Real-time RT-PCR analysis of LUZP2 mRNA expression in $\mathrm{LNCaP}$ and C4-2 cells. Columns, mean values among three replicates; error bars, $\mathrm{SD}$. $* * * P<0.001$. F and G. RT-qPCR analysis of expression of LUZP2 eRNA and mRNA in hormone-naïve (35) and castration-resistant (35V) PDXs (F) and expression of LUZP2 mRNA in human primary PC and CRPC tissues obtained from Mayo Clinic (G). Outliers were omitted from box plots. Columns, mean values among three replicates; error bars, SD. ${ }^{*} P<0.05$. 
In this study, using genome-wide AR ChIP-seq and RNA-seq approaches we identified a subset of AR-eRNAs that were elevated in enzalutamide-resistant cells but reduced in sensitive cells following long-term enzalutamide treatment. The loci of FTO, LUZP2, MARC1 and NCAM2 have been identified and further verified to be highly altered targets that may contribute to the development of enzalutamide resistance. It has been shown recently that AR-activated enhancers marked by increased eRNAs are responsible for activation of nearby coding transcription units [20]. In two (NCAM2 and MARC1) of these 4 target genes, we have successfully confirmed the existence of the interaction between eRNA-producing enhancers and the corresponding promoters using $3 \mathrm{C}$ assay. The enhancer/ promoter interactions in the loci of NCAM2 and MARC1 in C4-2 cells were induced by enzalutamide treatment, while this interaction was suppressed by enzalutamide in the locus of NCAM2 in LNCaP cells, suggesting that the activity of these enhancers are regulated by enzalutamide.

A significant finding from our functional studies is the potential role of $L U Z P 2$ in development of enzalutamide resistance in $\mathrm{C} 4-2$ cells. LUZP2 (leucine zipper protein 2 gene) encodes a leucine zipper protein that has been reported to be deleted in some patients with Wilms tumor-Aniridia-Genitourinary anomaliesmental Retardation (WAGR) syndrome, which is a rare congenital anomaly syndrome consisting of Wilm's tumor, aniridia, genitalanomalies and mental retardation [46, 47]. Its correlation with cancers including $\mathrm{PCa}$ has not yet been reported. However, our results show that LUZP2 knockdown induces cytotoxicity in enzalutamide-resistant C4-2 CRPC cells. Our finding for the first time identifies LUZP2 as a putative therapeutic target for the treatment of enzalutamide-resistant CRPC. Moreover, our data show that LUZP2 mRNA expression is upregulated in hormonenaïve $\mathrm{PC}$ compared with normal prostate tissues, but downregulated during the development from hormonenaïve PC to CRPC. However, it is upregulated again in enzalutamide-resistant CRPC compared with enzalutamideuntreated CRPC. Taken together, these results suggest an interesting gain, lose and re-gain of certain survival mechanisms during the tumorigenesis of $\mathrm{PC}$, the evolution from PC to CRPC and the development of enzalutamide resistance in CRPC. Future investigation of the underlying mechanisms is warranted. Notably, it has been reported that relative to low-grade PC, high-grade cancer shows an attenuated androgen signaling signature that is similar to metastatic PC, and decreased expression of AR-dependent genes was observed during PC progression [48]. Thus, LUZP2 gene expression pattern during PC progression resembles the phenomenon occurred in $\mathrm{PC}$ patients.

Another unexpected result of our study is the finding that MARC1 knockdown promotes growth of enzalutamideresistant CRPC C4-2 cells. The MARC1 gene encodes signal-anchored mitochondrial protein integrated into the outer mitochondrial membrane [49]. It is expressed in liver and omental and subcutaneous fat, and pathologically participates in superoxide-mediated oxidative stress [50], but the role of MARC1 in tumorigenesis and anticancer therapy resistance remains largely unknown. Our data show that eRNA expression at this locus was elevated after long-term enzalutamide treatment, which is consistent with enzalutamide treatment-induced increase in the interaction between its enhancer and promoter in C4-2 CRPC cells. These results imply that MARC1 may function as a negative regulator that antagonizes the development of enzalutamide resistance in CRPC cells. Thus, this gene could be utilized as a potential indicator for drug sensitivity and harnessed for treatment of enzalutamide-resistant CRPC.

A limitation in our study is that we only performed in depth analysis for a few AR-eRNAs. Further studies on the regulation of expression of more AR-eRNAs in hormone-naïve PC and CRPC as well as their roles in development of enzalutamide resistance are warranted in future.

\section{MATERIALS AND METHODS}

\section{Cell lines, cell culture and reagents}

LNCaP cells and human embryonic kidney 293T cells were purchased from ATCC (Manassas, VA). C4-2 cells were purchased from UroCorporation. LNCaP and C4-2 cells were cultured in RPMI 1640 medium supplemented with $10 \%$ fetal bovine serum (FBS) (Thermo Fisher Scientific) and $100 \mu \mathrm{g} / \mathrm{ml}$ penicillin-streptomycinglutamine (Thermo Fisher Scientific) at $37^{\circ} \mathrm{C}$ with $5 \%$ $\mathrm{CO}_{2}$. 293T cells were maintained in Dulbecco's modified Eagle's medium (Thermo Fisher Scientific) supplemented with 10\% fetal bovine serum (FBS) (Invitrogen) and 100 $\mu \mathrm{g} / \mathrm{ml}$ penicillin-streptomycin-glutamine (Thermo Fisher Scientific) at $37^{\circ} \mathrm{C}$ with $5 \% \mathrm{CO}_{2}$. Enzalutamide was kindly provided by Medivation/Astellas (San Francisco, CA). Mibolerone was purchased from Steraloids Inc (Newport, $\mathrm{RI})$. The antibody used for AR ChIP-seq is anti-AR (N20) from Santa Cruz Biotechnology. The antibodies used for western blot are anti-ERK2 (D-2, Santa Cruz Biotechnology), anti-LUZP2 (ab171165, Abcam) and antiMARC1 (D-16, Santa Cruz Biotechnology).

\section{Human prostate cancer specimens and RNA isolation from human tissues}

Formalin-fixed paraffin-embedded (FFPE) hormonenaïve primary $\mathrm{PC}$ and CRPC tissues were randomly selected from the Mayo Tissue Registry. Hormone-naïve patients with biopsy-proven PC have been treated at Mayo Clinic by radical retropubic prostatectomy between January 1995 and December 1998 without neoadjuvant therapy. The study was approved by the Mayo Clinic Institutional Review Board. FFPE tissues were collected and total RNAs were isolated using a RecoverAll Total Nucleic Acid Isolation Kit (Thermo Fisher Scientific). 


\section{Cell morphology analysis and photography}

LNCaP and C4-2 cells were treated with enzalutamide for 28 days and the morphological images were acquired using the Leica DMI3000 B microscope (Wetzlar, Germany) from at least 3 random fields. Scale bars, $100 \mu \mathrm{m}$.

\section{Cell viability (MTS) assay}

The MTS assays were performed according to manufacturer's instructions (Promega). Briefly, cells were plated in 96-well plates at a density of 2,000 cells per well. At the indicated times, $20 \mu \mathrm{l}$ of CellTiter 96R AQueous Solution Reagent (Promega) was added to each well, and incubated for $2 \mathrm{~h}$ at $37^{\circ} \mathrm{C}$ in incubator and then was measured in a microplate reader at $490 \mathrm{~nm}$.

\section{Chromatin immunoprecipitation (ChIP), ChIP- seq and data analysis}

ChIP was performed as described previously [51] using anti-AR antibody (N20, Santa Cruz Biotechnology). LNCaP and C4-2 cells were treated with mibolerone, a synthetic androgen $(1 \mathrm{nM})$ or ethanol for 3 days. ChIPseq libraries were prepared using the methods as described previously [52] and high throughput sequencing was performed using the Illumina HiSeq2000 platforms at the Mayo Genome Core Facility. The data were analyzed using the following pipeline: (1) Mapping. ChIP-seq raw reads were aligned to reference genome (GRCh37/hg19) using Burrows-Wheeler Alignment (BWA) tool [53]. (2) Quality control. Subsequent to alignments, the following factors were evaluated to ensure that the sequencing data were of sufficient quality for downstream applications: the number of reads that can be mapped to unique locations in the genome, the number of nonredundant reads and the saturation test of sequencing depth. The saturation test was used to decide if current sequencing depth is sufficient to capture all protein binding locations. (3) Peak detection and visualization. MACS [54] was used to perform peak calling because it has been demonstrated to work very well with sharp peaks for transcription regulatory proteins (such as AR). BigBed and BigWig files were generated to facilitate both easy processing and high performance visualization with the UCSC genome browser or IGV. Integration of AR ChIP-seq data with other published epigenetic datasets such as histone ChIPseq was performed using Epidaurus [55]. For ChIP-qPCR experiments, DNAs pulled down by antibodies were amplified by real-time PCR. Raw and processed data have been deposited into NCBI Gene Expression Omnibus with accession number GSE55032. Primer sequences are described in Supplementary Table 1.

\section{RNA-seq and data analysis}

LNCaP and C4-2 cells were plated in medium described above and after $24 \mathrm{~h}, 10 \mu \mathrm{M}$ enzalutamide or
DMSO was added, and the cells were treated for 28 days. Total RNAs were isolated from cells using the methods as described previously [56]. Briefly, RNA was isolated using RNeasy Plus Mini Kit (Qiagen). High quality (Agilent Bioanalyzer RIN > 7.0) total RNAs were employed for the preparation of sequencing libraries using Illumina TruSeq Stranded Total RNA/Ribo-Zero Sample Prep Kit. A total of 500-1,000 ng of riboRNA-depleted total RNA was fragmented by RNase III treatment at $37^{\circ} \mathrm{C}$ for $10-18 \mathrm{~min}$ and RNase III was inactivated at $65^{\circ} \mathrm{C}$ for $10 \mathrm{~min}$. Size selection (50 to $150 \mathrm{bp}$ fragments) was performed using the FlashPAGE denaturing PAGE-fractionator (Thermo Fisher Scientific) prior to ethanol precipitation overnight. The resulting RNA was directionally ligated, reversetranscribed and RNase $\mathrm{H}$ treated.

Samples with biological duplicates were sequenced using the Illumina HiSeq2000 platform at the Mayo Genome Core Facility. Pre-analysis quality control was performed using FastQC (http://www.bioinformatics. babraham.ac.uk/projects/fastqc/) and RSeQC software [57] to ensure that raw data are in excellent condition and suitable for downstream analyses. Pair-end raw reads were aligned to the human reference genome (GRch37/ hg19) using Tophat [58]. Genome-wide coverage signals were represented in BigWig format to facilitate convenient visualization using the UCSC genome browser. Gene expression was measured using RPKM (Reads Per Kilo-base exon per Million mapped reads) as described previously [59]. Correlation analyses between eRNA and mRNA expression were performed using Python and R scripts. EdgeR [60] was used to identify genes that were differentially expressed between CRPC and primary prostate tumors. Raw and processed data have been deposited into NCBI Gene Expression Omnibus with accession number GSE55032.

\section{Real-time RT-PCR}

Total RNA was isolated with Trizol reagent (Thermo Fisher Scientific) and cDNA was prepared using SuperScript II reverse transcriptase (Thermo Fisher Scientific). Quantitative real-time PCR was performed with iQ SYBR Green Supermix on iCycleriQTM detection system (Bio-Rad) according to manufacturer's instructions. The relative expression level of RNA was calculated by normalizing to glyceraldehyde-3-phosphate dehydrogenase (GAPDH) levels using the $2^{-\triangle \Delta C T}$ method. Primer sequences are described in Supplementary Table 1.

\section{$3 \mathrm{C}$ assay}

The 3C assay was performed as previously described with some modifications [61]. Long- or shortterm enzalutamide-treated $\mathrm{LNCaP}$ and $\mathrm{C} 4-2$ cells were fixed with $1 \%$ formaldehyde. Cell pellets were lysed and resuspended in restriction buffer for BanI and XhoI respectively for the loci of $N C A M 2$ and MARC1 and 
treated with $0.3 \% \mathrm{SDS}$ for $1 \mathrm{~h}$ at $37^{\circ} \mathrm{C}$. Triton $\mathrm{X}-100$ was added to a final concentration of $2 \%$ followed by overnight digestion of BanI and XhoI (1,500 U per $10^{7}$ cells) at $37^{\circ} \mathrm{C}$. DNA ligation was performed for $4 \mathrm{~h}$ at $16^{\circ} \mathrm{C}$. The ligated samples were reverse cross-linked with proteinase-K at $65^{\circ} \mathrm{C}$ overnight, followed by phenol/ chloroform extraction and ethanol precipitation. The primers for PCR are provided in Supplementary Table 1.

\section{Cell infection by shRNA and western blot}

Short hairpin RNAs (shRNA) specific for NCAM2, FTO, MARC1, LUZP2 and non-specific (NS) shRNA were purchased from Open Biosystems. 293T cells were transfected with shRNA constructs using Lipofectamine 2000 (Thermo Fisher Scientific). Supernatant containing virus particles was harvested 2 days after transfection and used for infection of enzalutamide-resistant C4-2 cells. Cells were harvested $48 \mathrm{~h}$ after infection. For western blot, briefly, protein samples were denatured and separated by SDS-polyacrylamide gel electrophoresis (SDS/PAGE), and then transferred to nitrocellulose membranes (BioRad). The membranes were immunoblotted with primary antibodies, horseradish peroxidase-conjugated secondary antibodies, and exposed to SuperSignal West Pico Stable Peroxide Solution (Thermo Fisher Scientific).

\section{Prostate cancer xenografts LuCaP35 and 35V}

Patient-derived androgen dependent (AD) LuCaP35 and castration-resistant (or androgen independent, AI) LuCaP35V xenograft models were kindly provided by Dr. Robert L. Vessella (Department of Urology, University of Washington Medical Center, Seattle, WA). AD LuCaP xenografts were propagated in $\mathrm{BALB} / \mathrm{c}$ nu/nu mice and AI xenografts were propagated in SCID mice. These experiments were performed in the laboratory of Dr. Donald Tindall at the Mayo Clinic. Mice were housed in the pathogen-free rodent facility at the Mayo Clinic. All procedures were approved by the Mayo Clinic Institutional Animal Care and Use Committee (IACUC).

\section{Statistics}

Experiments were carried out with two or more replicates unless otherwise stated. Data are expressed as the mean \pm standard deviation (SD) if not otherwise indicated, and compared using the independent Student's t-test. Values with $\mathrm{p}<0.05$ are considered statistically different.

\section{ACKNOWLEDGMENTS}

The authors thank Dr. Robert L. Vessella from the University of Washington Medical Center (Seattle, WA) and Dr. Donald J. Tindall at the Mayo Clinic for kindly providing tissues from LuCaP35 and LuCaP35V PDX models. This work was supported in part by grants from the NIH (CA134514, CA130908 \& CA193239 to H.H.); DOD (W81XWH-14-1-0486 to H.H.); 2015 Movember Foundation-Prostate Cancer Foundation Challenge Award (2015CHAL518 to H.H.); Medivation/Astellas (ENZA13F13 (000893) to H.H.); The T. J. Martell Foundation (to H.H.); Mayo Clinic CIM and CBD centers (to H.H.); Natural Science Foundation of China (81172541 to G. W.) and Natural Science Foundation of Jilin Province of China (201015139 to G. W.).

\section{CONFLICTS OF INTEREST}

The authors declare no conflicts of interest.

\section{REFERENCES}

1. Siegel RL, Miller KD, Jemal A. Cancer statistics, 2015. CA: a cancer journal for clinicians. 2015; 65:5-29.

2. Huggins C, Hodges CV. Studies on prostatic cancer. I. The effect of castration, of estrogen and androgen injection on serum phosphatases in metastatic carcinoma of the prostate. CA: a cancer journal for clinicians. 1972; 22:232-240.

3. Mohler JL, Gregory CW, Ford OH, 3rd, Kim D, Weaver CM, Petrusz P, Wilson EM, French FS. The androgen axis in recurrent prostate cancer. Clinical cancer research. 2004; 10:440-448.

4. Nelson PS. Molecular states underlying androgen receptor activation: a framework for therapeutics targeting androgen signaling in prostate cancer. Journal of clinical oncology. 2012; 30:644-646.

5. Knudsen KE, Penning TM. Partners in crime: deregulation of AR activity and androgen synthesis in prostate cancer. Trends in endocrinology and metabolism: TEM. 2010; 21:315-324.

6. Sternberg CN, Petrylak DP, Madan RA, Parker C. Progress in the treatment of advanced prostate cancer. American Society of Clinical Oncology educational book / ASCO American Society of Clinical Oncology Meeting. 2014:117-131.

7. Scher HI, Fizazi K, Saad F, Taplin ME, Sternberg CN, Miller K, de Wit R, Mulders P, Chi KN, Shore ND, Armstrong AJ, Flaig TW, Flechon A, Mainwaring P, Fleming M, Hainsworth JD, et al. Increased survival with enzalutamide in prostate cancer after chemotherapy. The New England journal of medicine. 2012; 367:1187-1197.

8. Sternberg CN, de Bono JS, Chi KN, Fizazi K, Mulders P, Cerbone L, Hirmand M, Forer D, Scher HI. Improved outcomes in elderly patients with metastatic castrationresistant prostate cancer treated with the androgen receptor inhibitor enzalutamide: results from the phase III AFFIRM trial. Annals of oncology. 2014; 25:429-434. 
9. Liu C, Lou W, Zhu Y, Yang JC, Nadiminty N, Gaikwad NW, Evans CP, Gao AC. Intracrine Androgens and AKR1C3 Activation Confer Resistance to Enzalutamide in Prostate Cancer. Cancer research. 2015; 75:1413-1422.

10. Yamamoto Y, Loriot Y, Beraldi E, Zhang F, Wyatt AW, Nakouzi NA, Mo F, Zhou T, Kim Y, Monia BP, MacLeod AR, Fazli L, Wang Y, Collins CC, Zoubeidi A, Gleave $\mathrm{M}$. Generation 2.5 antisense oligonucleotides targeting the androgen receptor and its splice variants suppress enzalutamide-resistant prostate cancer cell growth. Clinical cancer research. 2015; 21:1675-1687.

11. Heintzman ND, Hon GC, Hawkins RD, Kheradpour P, Stark A, Harp LF, Ye Z, Lee LK, Stuart RK, Ching CW, Ching KA, Antosiewicz-Bourget JE, Liu H, Zhang X, Green RD, Lobanenkov VV, et al. Histone modifications at human enhancers reflect global cell-type-specific gene expression. Nature. 2009; 459:108-112.

12. Heintzman ND, Stuart RK, Hon G, Fu Y, Ching CW, Hawkins RD, Barrera LO, Van Calcar S, Qu C, Ching KA, Wang W, Weng Z, Green RD, Crawford GE, Ren B. Distinct and predictive chromatin signatures of transcriptional promoters and enhancers in the human genome. Nature genetics. 2007; 39:311-318.

13. Pennacchio LA, Ahituv N, Moses AM, Prabhakar S, Nobrega MA, Shoukry M, Minovitsky S, Dubchak I, Holt A, Lewis KD, Plajzer-Frick I, Akiyama J, De Val S, Afzal $\mathrm{V}$, Black BL, Couronne O, et al. In vivo enhancer analysis of human conserved non-coding sequences. Nature. 2006; 444:499-502.

14. Visel A, Blow MJ, Li Z, Zhang T, Akiyama JA, Holt A, Plajzer-Frick I, Shoukry M, Wright C, Chen F, Afzal V, Ren B, Rubin EM, Pennacchio LA. ChIP-seq accurately predicts tissue-specific activity of enhancers. Nature. 2009; 457:854-858.

15. Core LJ, Waterfall JJ, Lis JT. Nascent RNA sequencing reveals widespread pausing and divergent initiation at human promoters. Science. 2008; 322:1845-1848.

16. Kim TK, Hemberg M, Gray JM, Costa AM, Bear DM, Wu J, Harmin DA, Laptewicz M, Barbara-Haley K, Kuersten S, Markenscoff-Papadimitriou E, Kuhl D, Bito H, Worley PF, Kreiman G, Greenberg ME. Widespread transcription at neuronal activity-regulated enhancers. Nature. 2010; 465:182-187.

17. Lupien M, Eeckhoute J, Meyer CA, Wang Q, Zhang Y, Li W, Carroll JS, Liu XS, Brown M. FoxA1 translates epigenetic signatures into enhancer-driven lineage-specific transcription. Cell. 2008; 132:958-970.

18. Gao N, Ishii K, Mirosevich J, Kuwajima S, Oppenheimer SR, Roberts RL, Jiang M, Yu X, Shappell SB, Caprioli RM, Stoffel M, Hayward SW, Matusik RJ. Forkhead box A1 regulates prostate ductal morphogenesis and promotes epithelial cell maturation. Development. 2005; 132:3431-3443.
19. Mirosevich J, Gao N, Matusik RJ. Expression of Foxa transcription factors in the developing and adult murine prostate. The Prostate. 2005; 62:339-352.

20. Wang D, Garcia-Bassets I, Benner C, Li W, Su X, Zhou Y, Qiu J, Liu W, Kaikkonen MU, Ohgi KA, Glass CK, Rosenfeld MG, Fu XD. Reprogramming transcription by distinct classes of enhancers functionally defined by eRNA. Nature. 2011; 474:390-394.

21. Dayon A, Brizuela L, Martin C, Mazerolles C, Pirot N, Doumerc N, Nogueira L, Golzio M, Teissie J, Serre G, Rischmann P, Malavaud B, Cuvillier O. Sphingosine kinase-1 is central to androgen-regulated prostate cancer growth and survival. PloS one. 2009; 4:e8048.

22. Martin-Orozco RM, Almaraz-Pro C, Rodriguez-Ubreva FJ, Cortes MA, Ropero S, Colomer R, Lopez-Ruiz P, Colas B. EGF prevents the neuroendocrine differentiation of $\mathrm{LNCaP}$ cells induced by serum deprivation: the modulator role of PI3K/Akt. Neoplasia. 2007; 9:614-624.

23. Zhang XQ, Kondrikov D, Yuan TC, Lin FF, Hansen J, Lin MF. Receptor protein tyrosine phosphatase alpha signaling is involved in androgen depletion-induced neuroendocrine differentiation of androgen-sensitive LNCaP human prostate cancer cells. Oncogene. 2003; 22:6704-6716.

24. Uysal-Onganer P, Kawano Y, Caro M, Walker MM, Diez S, Darrington RS, Waxman J, Kypta RM. Wnt-11 promotes neuroendocrine-like differentiation, survival and migration of prostate cancer cells. Molecular cancer. 2010; 9:55.

25. Yuan TC, Veeramani S, Lin FF, Kondrikou D, Zelivianski S, Igawa T, Karan D, Batra SK, Lin MF. Androgen deprivation induces human prostate epithelial neuroendocrine differentiation of androgen-sensitive LNCaP cells. Endocrine-related cancer. 2006; 13:151-167.

26. Berenguer C, Boudouresque F, Dussert C, Daniel L, Muracciole X, Grino M, Rossi D, Mabrouk K, FigarellaBranger D, Martin PM, Ouafik L. Adrenomedullin, an autocrine/paracrine factor induced by androgen withdrawal, stimulates 'neuroendocrine phenotype' in LNCaP prostate tumor cells. Oncogene. 2008; 27:506-518.

27. Jongsma J, Oomen MH, Noordzij MA, Van Weerden WM, Martens GJ, van der Kwast TH, Schroder FH, van Steenbrugge GJ. Different profiles of neuroendocrine cell differentiation evolve in the PC-310 human prostate cancer model during long-term androgen deprivation. The Prostate. 2002; 50:203-215.

28. Huss WJ, Gregory CW, Smith GJ. Neuroendocrine cell differentiation in the CWR22 human prostate cancer xenograft: association with tumor cell proliferation prior to recurrence. The Prostate. 2004; 60:91-97.

29. Jongsma J, Oomen MH, Noordzij MA, Van Weerden WM, Martens GJ, van der Kwast TH, Schroder FH, van Steenbrugge GJ. Androgen deprivation of the PC-310 [correction of prohormone convertase-310] human 
prostate cancer model system induces neuroendocrine differentiation. Cancer research. 2000; 60:741-748.

30. Jongsma J, Oomen MH, Noordzij MA, Van Weerden WM, Martens GJ, van der Kwast TH, Schroder FH, van Steenbrugge GJ. Kinetics of neuroendocrine differentiation in an androgen-dependent human prostate xenograft model. The American journal of pathology. 1999; 154:543-551.

31. Noordzij MA, van Weerden WM, de Ridder CM, van der Kwast TH, Schroder FH, van Steenbrugge GJ. Neuroendocrine differentiation in human prostatic tumor models. The American journal of pathology. 1996; 149:859-871.

32. Burgio SL, Conteduca V, Menna C, Carretta E, Rossi L, Bianchi E, Kopf B, Fabbri F, Amadori D, De Giorgi U. Chromogranin A predicts outcome in prostate cancer patients treated with abiraterone. Endocrine-related cancer. 2014; 21:487-493.

33. Conteduca V, Burgio SL, Menna C, Carretta E, Rossi L, Bianchi E, Masini C, Amadori D, De Giorgi U. Chromogranin A is a potential prognostic marker in prostate cancer patients treated with enzalutamide. The Prostate. 2014; 74:1691-1696.

34. Chen Z, Lan X, Thomas-Ahner JM, Wu D, Liu X, Ye Z, Wang L, Sunkel B, Grenade C, Chen J, Zynger DL, Yan PS, Huang J, Nephew KP, Huang TH, Lin S, et al. Agonist and antagonist switch DNA motifs recognized by human androgen receptor in prostate cancer. EMBO J. 2015; 34:502-516.

35. Grasso CS, Wu YM, Robinson DR, Cao X, Dhanasekaran SM, Khan AP, Quist MJ, Jing X, Lonigro RJ, Brenner JC, Asangani IA, Ateeq B, Chun SY, Siddiqui J, Sam L, Anstett $\mathrm{M}$, et al. The mutational landscape of lethal castrationresistant prostate cancer. Nature. 2012; 487:239-243.

36. Harris WP, Mostaghel EA, Nelson PS, Montgomery B. Androgen deprivation therapy: progress in understanding mechanisms of resistance and optimizing androgen depletion. Nature clinical practice Urology. 2009; 6:76-85.

37. Schweizer MT, Zhou XC, Wang H, Bassi S, Carducci MA, Eisenberger MA, Antonarakis ES. The influence of prior abiraterone treatment on the clinical activity of docetaxel in men with metastatic castration-resistant prostate cancer. European urology. 2014; 66:646-652.

38. Malik R, Khan AP, Asangani IA, Cieslik M, Prensner JR, Wang X, Iyer MK, Jiang X, Borkin D, EscaraWilke J, Stender R, Wu YM, Niknafs YS, Jing X, Qiao $\mathrm{Y}$, Palanisamy $\mathrm{N}$, et al. Targeting the MLL complex in castration-resistant prostate cancer. Nature medicine. 2015; 21:344-352.

39. Merseburger AS, Bellmunt J, Jenkins C, Parker C, Fitzpatrick JM. Perspectives on treatment of metastatic castration-resistant prostate cancer. The oncologist. 2013; 18:558-567.

40. Kirby M, Hirst C, Crawford ED. Characterising the castration-resistant prostate cancer population: a systematic review. International journal of clinical practice. 2011; 65:1180-1192.

41. Ngollo M, Dagdemir A, Karsli-Ceppioglu S, Judes G, Pajon A, Penault-Llorca F, Boiteux JP, Bignon YJ, Guy L, Bernard-Gallon DJ. Epigenetic modifications in prostate cancer. Epigenomics. 2014; 6:415-426.

42. Hah N, Danko CG, Core L, Waterfall JJ, Siepel A, Lis JT, Kraus WL. A rapid, extensive, and transient transcriptional response to estrogen signaling in breast cancer cells. Cell. 2011; 145:622-634.

43. Thurman RE, Rynes E, Humbert R, Vierstra J, Maurano MT, Haugen E, Sheffield NC, Stergachis AB, Wang H, Vernot B, Garg K, John S, Sandstrom R, Bates D, Boatman L, Canfield TK, et al. The accessible chromatin landscape of the human genome. Nature. 2012; 489:75-82.

44. Puc J, Kozbial P, Li W, Tan Y, Liu Z, Suter T, Ohgi KA, Zhang J, Aggarwal AK, Rosenfeld MG. Ligand-dependent enhancer activation regulated by topoisomerase-I activity. Cell. 2015; 160:367-380.

45. Hsieh CL, Fei T, Chen Y, Li T, Gao Y, Wang X, Sun T, Sweeney CJ, Lee GS, Chen S, Balk SP, Liu XS, Brown M, Kantoff PW. Enhancer RNAs participate in androgen receptor-driven looping that selectively enhances gene activation. Proc Natl Acad Sci U S A. 2014; 111:7319-7324.

46. Wu M, Michaud EJ, Johnson DK. Cloning, functional study and comparative mapping of Luzp2 to mouse chromosome 7 and human chromosome 11p13-11p14. Mamm Genome. 2003; 14:323-334.

47. Fischbach BV, Trout KL, Lewis J, Luis CA, Sika M. WAGR syndrome: a clinical review of 54 cases. Pediatrics. 2005; 116:984-988.

48. Tomlins SA, Mehra R, Rhodes DR, Cao X, Wang L, Dhanasekaran SM, Kalyana-Sundaram S, Wei JT, Rubin MA, Pienta KJ, Shah RB, Chinnaiyan AM. Integrative molecular concept modeling of prostate cancer progression. Nat Genet. 2007; 39:41-51.

49. Klein JM, Busch JD, Potting C, Baker MJ, Langer T, Schwarz G. The mitochondrial amidoxime-reducing component (mARC1) is a novel signal-anchored protein of the outer mitochondrial membrane. J Biol Chem. 2012; 287:42795-42803.

50. Ghorbel MT, Mokhtari A, Sheikh M, Angelini GD, Caputo M. Controlled reoxygenation cardiopulmonary bypass is associated with reduced transcriptomic changes in cyanotic tetralogy of Fallot patients undergoing surgery. Physiological genomics. 2012; 44:1098-1106.

51. Zhao Y, Wang L, Ren S, Blackburn PR, McNulty MS, Gao X, Qiao M, Vessella RL, Kohli M, Zhang J, Karnes RJ, Tindall DJ, Kim Y, MacLeod R, Ekker SC, Kang T, et al. Activation of P-TEFb by Androgen Receptor-Regulated Enhancer RNAs in Castration-Resistant Prostate Cancer. Cell Rep. 2016; 15:599-610.

52. Boyer LA, Lee TI, Cole MF, Johnstone SE, Levine SS, Zucker JP, Guenther MG, Kumar RM, Murray HL, Jenner 
RG, Gifford DK, Melton DA, Jaenisch R, Young RA. Core transcriptional regulatory circuitry in human embryonic stem cells. Cell. 2005; 122:947-956.

53. Li H, Durbin R. Fast and accurate short read alignment with Burrows-Wheeler transform. Bioinformatics. 2009; 25:1754-1760.

54. Zhang Y, Liu T, Meyer CA, Eeckhoute J, Johnson DS, Bernstein BE, Nusbaum C, Myers RM, Brown M, Li W, Liu XS. Model-based analysis of ChIP-Seq (MACS). Genome biology. 2008; 9:R137.

55. Wang L, Huang H, Dougherty G, Zhao Y, Hossain A, Kocher JP. Epidaurus: aggregation and integration analysis of prostate cancer epigenome. Nucleic acids research. 2014.

56. Wang L, Zeng X, Chen S, Ding L, Zhong J, Zhao JC, Sarver A, Koller A, Zhi J, Ma Y, Yu J, Chen J, Huang H. BRCA1 is a negative modulator of the PRC2 complex. The EMBO journal. 2013; 32:1584-1597.
57. Wang L, Wang S, Li W. RSeQC: quality control of RNAseq experiments. Bioinformatics. 2012; 28:2184-2185.

58. Trapnell C, Pachter L, Salzberg SL. TopHat: discovering splice junctions with RNA-Seq. Bioinformatics. 2009; 25:1105-1111.

59. Mortazavi A, Williams BA, McCue K, Schaeffer L, Wold B. Mapping and quantifying mammalian transcriptomes by RNA-Seq. Nature methods. 2008; 5:621-628.

60. Robinson MD, Oshlack A. A scaling normalization method for differential expression analysis of RNA-seq data. Genome Biol. 2010; 11:R25.

61. Hagege H, Klous P, Braem C, Splinter E, Dekker J, Cathala G, de Laat W, Forne T. Quantitative analysis of chromosome conformation capture assays (3C-qPCR). Nature protocols. 2007; 2:1722-1733. 